\title{
Duas espécies novas de Paratrigona da Reyião Amazônica (Hymenoptera, Apidae) ${ }^{1}$
}

\author{
Jesús S antiago Moure ${ }^{2}$
}

\begin{abstract}
Two species of Paratrigona - myrmecophila $s p$. $n$. and pannosa sp. n. - from Amazonian region are described.

Recebi do Professor Sebastião Laroca exemplares de uma espécie de Paratrigona achada em um ninho de Camponotus que considero como nova. Revendo o conceito estrito de Paratrigona opaca e Paratrigona peltata, descrevo também como nova a forma do Leste Amazônico, cujas operárias têm desenhos mais reduzidos que essas espécies.

\section{Paratrigona myrmecophila sp. n.}

Pertence ao grupo de espécie peltata, opaca, guatemalensis, pacifica e lophocoryphe, com a área malar distinta (aproximadamente a metade do diâmetro do ocelo médio, ou do segundo flagelômero), o clípeo curto (pouco mais de um terço da distância clipeocelar), a carena pós-ocelar evidente porém não elevado-laminada como em lophocoryphe. Na chave de Schwarz (1948: 353-355) entra no dilema 12, ficando próxima à pacífica, da qual difere pelos desenhos amarelos (principalmente a fina estria parocular com interrupções e distalmente separada da curtissima e fina estria justaclipeal, confinada à margem da fóvea tentorial). Separa-se de todo o grupo pelo escapo mais inchado, lembrando subnuda.
\end{abstract}

\section{OPERÁRIA}

TAMANHO - Comprimento total aproximado $3,8 \mathrm{~mm}$; da asa anterior $3,2 \mathrm{~mm}$; largura da cabeça $1,7 \mathrm{~mm}$, do segundo segmento abdominal $1,6 \mathrm{~mm}$.

Preta, com desenhos de um amarelo vivo: no clípeo com estria escura encurtada distalmente e unida na base pela porção escura da mancha supraclipeal em acento circunflexo " " " de ramos grossos;

1 Contribuição n: 660 do Departamento de Zoologia, do Setor de Ciências Biológicas, da UFPR.

2 Bolsista do CNPq. Professor Emérito. Departamento de Zoologia, da Universidade Federal do Paraná - CX. P. 19020, 81504 Curitiba - Pr. 
as estrias paroculares justaorbitais muito finas com larga interrupção ao nível um pouco superior ao dos alvéolos encurtados em baixo e largamente separados das estrias justaclipeais, reduzida ao curto trecho marginando a fóvea tentorial; estreita estria ao longo de todo o escapo, e a margem do flagelômero basal; larga faixa pronotal interrompida no meio, encurtada aos lados, separada dos lobos pronotais; nestes em forma de lágrimas muito estreitada para cima no terço superior; uma fina estria marginando todo o mesoscuto lateralmente, na frente completa e um pouco virada para dentro, quase ligada à marginal das axilas e estas à que contorna todo o bordo livre do escutelo; uma estria moderadamente larga ao longo da face externa das tíbias anteriores'e médias, mais atenuada na metade distal e ao longo do bordo posterior das tíbias posteriores, encurtada distalmente e alargada para a base; minúsculas manchas distais nos fêmures, um pouco mais evidentes nos posteriores. Tégulas escuras com mancha amarela triangular com fina interrupção transversal; asas subhialinas, mais escurecidas para o ápice com pterostigma e veias bastante escuros, com as células marginais primeira e segunda bastante evidentemente destacadas, e com manchas amarelas pequenas no esclerito costal, base proximal da $\mathrm{C}+\mathrm{Sc}$ e bordo interno do pterostigma.

Pilosidade reduzida a uma micropulverulência, visível apenas em certa luz, na maior parte do corpo; micropulverulência esta, descrita por Schwarz - para $P$. subnuda (p.365) - como "there is a sericeus sheen due to the presence over most of the head of dense, appressed, very microscopic, silvery gray hairlets". Na face ventral é notável, até 400 micrômetros. Pilosidade um pouco mais notável nas genas para baixo, no ocipício, no lado ventral do tórax, flancos do propódeo e esternos abdominais: os pelinhos amarelos esbranquiçados. No ocipício chegando até 100 micrômetros, nos flancos do propódeo mais curtos, no último tergo alguns até 60 micrômetros; os marginais distais corbiculares podendo chegar a 300 micrômetros.

Pontuação nåo evidente, apenas o micro-reticulado típico deste gênero; mais fina na face um pouquinho mais rugulosa no mesoscuto e escutelo, as microareolas mais evidentes na área basal do propódeo; o pontilhado muito fino, e os intervalos iguais e mais brilhantes nos tergos, com $50 \mathrm{x}$ em certa luz, os pontinhos dos tergos muito evidentes.

Cabeça pouco mais larga que o tórax, este praticamente tão largo como o abdomen $\left(2^{\circ}\right.$ tergo). Olho 2,3 vezes mais longo que largo (120:52); a interorbital máxima menor que o comprimento do ocelo e as órbitas mais convergentes embaixo (96:114:85); o clípeo curto, menos da metade de sua largura apical e pouco mais longo que um terço da distância clípeocelar (36:80:102); área malar evidente, seu comprimento cerca da metade do diâmetro do $2^{\circ}$ flagelômero; distância interalveolar igual ao diâmetro do alvéolo, um pouco menos que a alveolorbital e um pouco maior que um sexto da alveolocelar (16:16:22:90); a fronte muito desenvolvida, deprimido-sulcada ao longo do meio, a elevação supraclipeal em triângulo muito estreito e alongado; a distância interocelar mais de duas vezes o diâmetro do ocelo médio, claramente maior que a ocelorbital (32:14:21); o vértice elevado em carena grossa por trás dos ocelos, 
pouco demarcada anteriormente. O labro em arco muito rebaixado, simplesmente abaulado, pontilhado e com alguns pêlos na porção anterior; as mandíbulas quadridentadas, os dois primeiros dentes unidos por fina lâmina cortante, o terceiro e quarto bem destacados, a emarginação entre elas angulosa; o escapo curto e robusto, um pouco engrossado no meio, pouco mais da metade do comprimento do flagelo + pedicelo $(58: 15: 112)$; o primeiro flagelômero muito curto, os dois seguintes aumentando progressivamente, porém o diâmetro sempre maior que o comprimento (6:8:9:15). Escutelo mais longo que a metade de sua largura máxima entre as pontas das axilas (47:80), de contorno parabolóide muito arredondado, levissimamente emarginado no meio, a sutura-escutelar profunda, de fundo liso, levemente mais alongada no meio, tíbia posterior subtriangular, sua largura máxima menos da metade de seu comprimento (120:50) e tão longa como o olho; a corbícula atingindo os quatro nonos apicais da tíbia; o basitarso um pouco atenuado para o ápice, fortemente estreitado na base, com o canto posterior em ângulo fracamente agudo, um pouco mais estreito que a metade de seu comprimento e mais curto que os distitarsos em conjunto (60:28:70); o basitarso II bem mais longo que duas vezes sua largura $(48: 20)$.

Holótipo e 108 parátipos de um mesmo ninho, encontrado em Cachoeira de Samuel, Porto Velho, RO, Brasil, por S. Laroca e F. Giacomel, em novembro de 1988. Detalhes do ninho e comportamento em trabalho de Laroca \& Almeida.

A carena elevada pós-ocelar é como em $P$. pacifica (Schwarz, 1943), simpátrica. Tenho exemplares desta última de Pachitae, Valle do Chanchamayo, Tingo Maria e Iquitos no Perú, e de Rio Branco, AC - Brasil, Pimenta Bueno, RO - Brasil e de Nigrillani, N - Yungas, Bolívia, entre os quais um parátipo do Valle Chanchamayo, Perú, $800 \mathrm{~m}$, Weyrauch leg., II - 1939. Estas duas espécies se separam facilmente pelos desenhos amarelos da face: em, pacifica, as estrias paroculares justaorbitais são mais largas, inteiras e alargadas para baixo, ligadas largamente em "V" com as justaclipeais; a mancha supraclipeal é em trapézio sólido e as barras escuras no clípeo na maior parte dos espécimens chega a dividir a mancha clipeal em três. O exemplar de Nigrillani $(2.500 \mathrm{~m})$ é em tudo igual aos dos Perú e do Brasil, com a mancha supraclipeal quase triangular, o ápice muitc estreitamente truncado, e o escapo um pouco engrossado (62:14); entretanto a carena pós-ocelar é menos evidente e as estrias paroculares inteiras, fortes e muito alargadas no "V" distal. No exemplar de Pimenta Bueno, as estrias paroculares mais finas, inteiras e formando um "J" distal (lado direito). Em guatemalensis (Schwarz, 1938), as estrias paroculares são finas e inteiras, porém claramente separadas da curta estria justafoveal como em murmecophila; entretanto o desenho do clípeo e supraclipeal muito reduzidos e do escutelo mais curto (90:52) (exemplar de S. Pedro de Yepocapa, Dept. Chimalten, V - 1943, G.D. Fairchild).

Paratrigona opaca (Cockerell, 1917) descrita do Panamá, encontrada 
em colônia de Dolichoderus teve seu significado bastante ampliadọ por Schwarz, 1948. Para os exemplares, do Pará verificamos o existência de um nome anterior - peltata (Spinola, 1853), e que facilmente se separa de opaca, pela fina estria amarela anteocelar na fronte, os desenhos faciais e torácicos bem desenvolvidos (a parocular alargada para baixo e formando grosso " $\mathrm{V}$ " com a justaclipeal, a premarginal do clípeo inteira, etc...) e principalmente pelo escutelo mais longo-parabolóide $(52: 84)$ ainda mais longo proporcionalmente que em myrmecophila (,5875:,6190), não emarginado apicalmente, e a sutura escuto-escutelar estreita.

No Pará e Amazonas há uma variante de opaca que separamos mais abaixo, pela redução dos desenhos amarelos. Porém a verdadeira opaca da América Central e provavelmente os exemplares de Muzo, Colômbia (estes também em colônias de Dolichoderus bispinosus) possuem desenhos bem diferenciados: a faix a premarginal do clípeo relativamente bem alargada para os lados, sem estria mediana, antes um pequeno entalhe quase separando em duas a premarginal; as paroculares ligadas em " $V$ " distalmente às estrias justaclipeais; a supraclipeal em chapeu truncado superiormente, toda a face anterior do escapo; a estria que contorna o mesoscuto, axilas e escutelo, um pouco mais larga que as paroculares, porém mais estreita que o diâmetro do ocelo (6:10:16); o escutelo parabolóide $(76: 48: 0,631)$ com a extremidade apical ligeiramente sinuada, porém a sutura escuto-escutelar estreita. O desenho de Schwarz (1948, fig. 54 c) lembra exemplares do Amazonas (Manaus), Pará (Óbidos) e Amapá (Serra do Navio), que chamo Paratrigona pannosa sp. n.

Paratrigona pannosa sp. n.

\section{OPERÁRIA}

TAMANHO - Comprimento total aproximado $3,85 \mathrm{~mm}$, da asa anterior $3,25 \mathrm{~mm}$; largura da cabeça $1,7 \mathrm{~mm}$ e do segundo segmento abdominal $1,60 \mathrm{~mm}$.

Preta pardacenta, com desenhos amarelos: a faixa premarginal do clípeo em duas lágrimas transversais separadas no meio;as paroculares estreita em “ L ", completas, porém desligadas dos traços justaclipeais, a supraclipeal em acento circunflexo fino, a faixa anterior do escapo e grande parte do primeiro flagelômero e vestígios no segundo; uma faixa posterior no pronoto, interrompida e pouco separada dos lobos pronotais, nestes muito atenuada para cima; a estria que margina os lados do mesoscuto e das axilas e todo o contorno externo do escutelo, mais larga que a estria parocular; minúsculas manchas distais no ápice dos fêmures e uma estria na face externa das tíbias I e II, atenuadas para baixo e aí bastante encurtadas; ao longo do bordo posterior das tíbias III atenuado-encurtadas para baixo. Tégulas pardas com manchas triangular na metade anterior; asas subhialinas, levemente escurecidas para o ápice, as veias e pterostigma pretos, as duas primeiras células 
Vol. 6(3), 1989

submarginais bastante destacadas; com pequena mancha amarela no esclerito costal.

Pilosidade como na espécie anterior, curtíssima e formando pulverulência menos evidente na fronte e no mesonoto; pouco mais desenvolvida nas genas e ocipício e principalmente nos mesepisternos com pêlos até 300 micrômetros, nos flancos do propódeo e nos esternos abdominais.

Pontuação pouco evidente no micro-reticulado típico deste gênero, no mesoscuto e escutelo as carênulas um pouco mais evidente, e o areolado microscópico da área basal do propódeo bem destacado; nos tergos com pontilhado finissimo, denso.

A cabeça mais larga que longa $(170: 150)$, um pouco mais larga que o tórax e este praticamente tão largo como o abdomen (II segmento). Olho mais longo que duas vezes suas largura máxima (120:55), a interorbital máxima quase tão grande como o comprimento do olho e as órbitas mais convergentes embaixo (95:118:87); o clípeo curto, menos da metade de sua largura e pouco mais de três oitavos da distância clípeocelar (40:86:105); área malar evidente (5-6) cerca de um terço do diâmetro do ocelo médio; distância interalveolar um pouco maior que o diâmetro do alveolo, pouco mais de dois terços da alveolorbital, a alveolocelar lateral pouco mais de cinco vezes essa distância (18:16:26:96); a fronte muito desenvolvida, sulcado-deprimida antes do ocelo, o fundo da depressão em estreita linha lisa e com carênula vestigial junto ao ocelo; a distância interocelar duas vezes o diâmetro do ocelo médio, claramente maior que a ocelorbital (30:15:22); o vértice elevado em grossa carena pós-ocelar pouco demarcada anteriormente. O labro em arco muito rebaixado, simplesmente abaulado; as mandíbulas quadridentadas, sem lâmina intercalar entre dois primeiros (como no desenho de opaca); o escapo cinco vezes mais longo que largo, um pouco mais curto que a metade do flagelo e pedicelo juntos $(55: 11: 115)$, o primeiro flagelômero claramente mais longo que o segundo, ligeiramente superando o terceiro (10:7:9), flagelômeros mais curtos que seu diâmetro (14), exceto o distal. Escutelo tão longo como cinco oitavos da sua largura (50:80), de contorno perfeitamente parabolóide, a sutura escutoscutelar fina estreitamente brilhante no fundo. Tíbia posterior subtriangular, um pouco mais longa que os olhos e 2,7 vezes sua largura distal (125:47); o basitarso quase duas vezes mais longo que largo (55:28), o contorno posterior recurvo e o canto distal em ângulo agudo, os distitarsos em conjunto mais longos; o basitarso médio um pouco mais longo que duas vezes sua largura $(50-22)$.

Holótipo e três parátipos da Serra do Navio, Amapá-Brasil, um parátipo de Óbidos, PA e três de Manaus, AM, depositados em minha coleção, no Departamento de Zoologia (DZ) da Universidade Federal do Paraná.

Há uma pequena variação nas manchas amarelas, as do clípeo ficando as vezes reduzidas aos cantos inferiores, as justafoveais muito pequenas 
e a supraclipeal curtamente disjunta no vértice. Mais próxima de opaca, porém nesta última o bordo posterior do escutelo com sinuosidade fraca porém evidente na extremidade posterior, e os desenhos mais desenvolvidos no clípeo.

\section{REFERÊNCIAS}

MOURE, J.S. 1963. Sobre o identidade dos meliponinos descritos por Spinola em 1853 (Hymenoptera, Apoidea). An. Acad. Brasil. Ciências 35 (2): 257-269.

SCH WARZ, H.F. 1948. Stingless bees (Meliponinae) of the Western Hemisphere. Lestrimelitta and folowing subgenera of Trigona: Trigona, Parat rigona, Cephalotrigona, Oxytrigona, Scaura and Mourella. Bull. Amer. Mus. Nat. Hist. 90, i-xviii, 1-546 pp. 